Produto \& Produção, vol. 16 n.2, p.93-113, jun. 2015

RECEBIDO EM 05/06/2014. ACEITO EM 29/05/2015.

\title{
Lean Healthcare: uma análise da literatura
}

\author{
Carla Beatriz da Luz Peralta \\ Universidade Federal de Santa Catarina - UFSC \\ carlablp@gmail.com
}

Fernando Antonio Forcellini

Universidade Federal de Santa Catarina - UFSC

forcellini@gmail.com

\section{RESUMO}

Este artigo tem como objetivo, analisar na literatura qualificada estudos referentes a filosofia Lean aplicada aos serviços de saúde, a fim de verificar como esta filosofia tem sido trabalhada na prática. Trata-se de uma pesquisa teórica, com base na revisão bibliográfica sistemática, que recorre a recursos tecnológicos para indexação dos artigos do portfólio com o uso do software Endnote Basic. Desta forma, o portfólio final ficou composto por 61 artigos. Os artigos descrevem as fases iniciais da implementação da filosofia, e todos eles relatam resultados positivos. Este artigo contribuiu para tecer um panorama da produção acadêmica desta temática bem como tendências de estudo.

Palavras-chave: lean, revisão bibliográfica, saúde.

\begin{abstract}
This article aims to analyze the literature studies concerning qualified Lean philosophy applied to health services in order to see how this philosophy has been worked out in practice. This is a theoretical study, based on a systematic literature review, which uses technology to indexing of articles Portfolio using the Basic Endnote software. Thus, the final portfolio was composed of 61 items. The articles describe the initial stages of implementation of philosophy, and all of them reported positive results. This article contributed to weave an overview of academic research as well as trends of this thematic study.
\end{abstract}

Key-words: lean, literature review, health

\section{Introdução}

Os termos Lean Manufacturing, Toyota Production System, Lean Production, Lean Thinking e Manufatura Enxuta são todos sinônimos para uma mesma filosofia. Os autores Womack e Jones (1991) anunciaram no ocidente a filosofia de produção criada por Tahichi Ohno (Toyota, 1950). Inicialmente conhecida como Toyota Production System, a filosofia de Ohno foi nomeada por Womack e Jones de Lean Manufaturing. 
Após a segunda guerra mundial Taiichi Ohno, reconheceu que o sistema de produção em massa (fordismo) não era apropriado para as condições do mercado japonês (IMAI, 1986). Pois nesta época, as condições financeiras das indústrias japonesas se encontravam em situações adversas, desta forma, era importante reduzir os custos associados à produção. Além do que o Japão era um mercado pequeno, porém demandava uma enorme diversidade de produtos finais, por não possuir uma escala todos os veículos eram desenvolvidos na mesma linha de montagem, isso resultou na flexibilidade da Toyota em termos de mix e volume de produtos (WOMACK \& JONES, 1992).

Na década de 80 , a Toyota se mostrou ao mundo como uma potência na produção de veículos, apresentando também, toda sua gestão de operações com técnicas diferenciadas. Neste sentido, como aconteceu na produção em massa que praticamente extinguiu a produção artesanal, a produção enxuta vem realizando o mesmo com a produção em massa (WOMACK \& JONES, 1992).

Desta forma, hoje em dia, o Lean se difundiu pelo mundo coorporativo e está cada vez mais se tornando peça fundamental para a sustentabilidade das empresas em termos de competitividade, qualidade, custo, redução de lead time, agilidade e flexibilidade. Apesar de a filosofia Lean ter sido originada na manufatura, os autores Womack et al., (2005), destacam que: "o pensamento enxuto não é uma tática da manufatura ou de um programa de redução de custos, mas sim uma estratégia de gestão que é aplicável a todas organizações, por que tem a ver com a melhoria de processos. Todas organizações, incluindo as de saúde são compostas por uma série de processos, ou conjunto de ações destinadas à criação de valor para aqueles que usam ou dependem deles (clientes/pacientes)".

Conforme Graban (2008), os hospitais de um modo geral estão sofrendo constantemente com as novas demandas por parte do mercado. Onde os custos estão aumentando, muitas vezes com um gradiente bem maior que as receitas. Paralelamente a isto, erros frequentes que poderiam ser evitados vêm aumentando, e acabam prejudicando e até mesmo levando ao óbito pacientes.

Neste sentindo há o Lean Healthcare para contribuir para tal problema, pois este se constitui em um conjunto de conceitos, técnicas, ferramentas que melhoram a maneira como os hospitais são organizados e gerenciados (GRABAN, 2008). Dada a importância do Lean Healthcare, este artigo tem como objetivo analisar na literatura qualificada estudos referentes a esta temática, a fim de verificar como esta filosofia tem sido trabalhada na prática.

\section{Procedimentos metodológicos}

O método utilizado nesta pesquisa foi o teórico-conceitual, com base na revisão bibliográfica sistemática. No que se refere aos procedimentos e técnicas utilizados, trata-se de uma pesquisa bibliográfica, que recorre a recursos tecnológicos para identificação, seleção e indexação dos artigos científicos do portfólio com a utilização do software Endnote Basic.

De acordo com Kitchenham (2004), este tipo de revisão proporciona uma avaliação a respeito de um tópico de pesquisa, fazendo uso de uma metodologia de revisão que seja confiável, rigorosa e que permita auditagem. A Figura 1 apresenta as etapas em que foram divididas a revisão.



Figura 1 - Etapas da pesquisa 
No primeiro passo, ocorreu a seleção das bases de dados para busca dos artigos. Foi levado em conta as 22 bases de dados associadas com a Engenharia de Produção contidas no site Periódicos Capes (retirando as bases que tratavam de patentes). Desta forma, duas bases foram escolhidas, sendo elas, Scopus e a Web of Science, por terem a maior parte artigos publicados internacionalmente. Após, as palavras-chave foram determinadas e realizou-se um teste para verificar se a quantidade de artigos retornados seria suficiente para o estudo. As palavras-chave utilizadas foram: lean healthcare, healthcare toyota, lean hospitals, lean healthcare methodology, lean healthcare system, lean healthcare management $\mathrm{e}$ lean thinking in healthcare.

No segundo passo, foram levantados critérios para a busca de artigos nas bases (conforme Tabela 1). Em um primeiro momento, realizou-se uma busca por todas publicações que continham (lean healthcare, healthcare toyota, lean hospitals, lean healthcare methodology, lean healthcare system, lean healthcare management e lean thinking in healthcare), no título, resumo e palavraschave, o que resultou em 755 publicações na Web of Science e 63 na Scopus. Em seguida, foi feito um filtro selecionando-se somente artigos, nos idiomas inglês e português, utilizando todos anos o resultado foi de 646 artigos na Web of Science e 44 na Scopus. Com a utilização do Endnote Basic foram encontradas duplicações dos artigos, desta forma, ficaram ao todo 678 artigos, definindo assim, o portfólio desta pesquisa.

Tabela 1 - Critérios para a busca de artigos

\begin{tabular}{l|l|c}
\hline \multicolumn{1}{c|}{ Critérios para a busca } & \multicolumn{1}{c|}{ Observações } & Total de artigos \\
\hline Palavras-chaves & Título, resumo e palavras-chave & 818 \\
\hline Tipo e idioma & Artigo/ inglês ou português & 690 \\
\hline Utilizando Endnote & Encontrando duplicações & 678 \\
\hline
\end{tabular}

Finalmente para o último passo, foi feito uma pré-seleção de artigos, para isto foi necessário realizar leitura dos títulos, resumos e palavras-chave, dos 678 documentos. Com objetivo de desenvolver um portfólio de artigos importantes, ou seja, que melhor caracterizam o tema pesquisado, a fim de serem lidos para posteriormente realizar análise de conteúdo e construção de indicadores bibliométricos.

Após a leitura destes tópicos, 116 documentos estavam de acordo com a temática, porém 42 não permitiam o acesso gratuito, limitando o portfólio. Desta forma, o portfólio ficou composto por 74 artigos. Com o portfólio final definido, foi realizada a recuperação dos artigos para posterior leitura completa. No que diz respeito, a análise da literatura esta teve como objetivo estabelecer alguns dados bibliométricos, mas o foco principal foi à análise de conteúdo.

\section{Resultados}

\subsection{Análise bibliométrica}

A análise bibliométrica do Conjunto de Dados (CD) constituído por 74 artigos, consiste na análise e interpretação por meio de estatísticas simples: quantidade de artigos por periódicos, quantas vezes os artigos foram citados e quantidade de documentos por ano. Para primeira análise, identificaram-se os periódicos de destaque dentre os artigos que compõe o CD. Obteve-se 57 periódicos distintos, destacando entre eles os periódicos "Quality \& safety in health care" com 5 documentos (Tabela 2).

Tabela 2 - Periódicos em destaque

\begin{tabular}{l|c}
\multicolumn{1}{c|}{ Periódico } & $\begin{array}{c}\text { Quantidade } \\
\text { de Artigos }\end{array}$ \\
\hline Academic emergency medicine & 1 \\
\hline African journal of business management & 1 \\
\hline American journal of clinical pathology & 1 \\
\hline American journal of health-system pharmacy & 2 \\
\hline American journal of medical quality & 2 \\
\hline Anaesthesia & 1 \\
\hline
\end{tabular}




\begin{tabular}{|c|c|}
\hline Periódico & $\begin{array}{l}\text { Quantidade } \\
\text { de Artigos }\end{array}$ \\
\hline Annals of emergency medicine & 1 \\
\hline Annals of thoracic surgery & 1 \\
\hline Australian health review & 1 \\
\hline BMC health services research & 3 \\
\hline BMJ quality \& safety & 1 \\
\hline British journal of health care management & 1 \\
\hline Bulletin of the world health organization & 1 \\
\hline Business horizons & 1 \\
\hline Canadian journal of emergency medicine & 1 \\
\hline Development and learning in organisations & 1 \\
\hline Emergency medicine australasia & 1 \\
\hline Emj-engineering management jornal & 1 \\
\hline European journal of câncer & 1 \\
\hline European journal of internal medicine & 1 \\
\hline European journal of operational research & 1 \\
\hline European journal of radiology & 1 \\
\hline Fujitsu scientific \& technical jornal & 1 \\
\hline Health affairs & 1 \\
\hline Injury-international journal of the care of the injured & 1 \\
\hline International journal for quality in health care & 1 \\
\hline International journal of engineering business management & 1 \\
\hline International journal of health care quality assurance & 3 \\
\hline International journal of operations \& production management & 1 \\
\hline International journal of productivity and performance management & 1 \\
\hline $\begin{array}{l}\text { Journal for healthcare quality: official publication of the national } \\
\text { association for healthcare quality }\end{array}$ & 3 \\
\hline Journal of healthcare information management: JHIM & 1 \\
\hline Journal of hospital medicine & 1 \\
\hline Journal of molecular diagnostics & 2 \\
\hline Journal of nursing administration & 1 \\
\hline Journal of nursing management & 1 \\
\hline Journal of operations management & 1 \\
\hline Journal of psychosomatic research & 1 \\
\hline Journal of the american college of surgeons & 1 \\
\hline Journal of trauma-injury infection and critical care & 1 \\
\hline Journal of vascular surgery & 1 \\
\hline Labmedicine & 2 \\
\hline Leadership in health services & 2 \\
\hline Measuring business excellence & 1 \\
\hline Medical journal of australia & 2 \\
\hline Metalurgia international & 1 \\
\hline $\begin{array}{l}\text { Perspectives in health information management / ahima, american health } \\
\text { information management association }\end{array}$ & 1 \\
\hline Plos one & 1 \\
\hline Quality \& safety in health care & 5 \\
\hline Quality and reliability engineering international & 1 \\
\hline Radiographics & 1 \\
\hline Safety Science & 1 \\
\hline Social science \& medicine & 2 \\
\hline Stroke & 1 \\
\hline Supply chain management-an international journal & 1 \\
\hline Systems engineering & 1 \\
\hline Transfusion & 1 \\
\hline
\end{tabular}


A segunda análise, refere-se a quantidade de vezes que os artigos do conjunto de dados foram citados, conforme Tabela 3.

Tabela 3 - Quantidade de vezes que os artigos foram citados

\begin{tabular}{|c|c|c|}
\hline Artigo & Título & $\begin{array}{c}\mathbf{N}^{0} \text { de } \\
\text { citações }\end{array}$ \\
\hline 1 & $\begin{array}{l}\text { Lean principles optimize on-time vascular surgery operating room starts and } \\
\text { decrease resident work hours }\end{array}$ & 1 \\
\hline 2 & $\begin{array}{l}\text { The A3 Problem Solving Report: A 10-Step Scientific Method to Execute } \\
\text { Performance Improvements in an Academic Research Vivarium }\end{array}$ & $\mathrm{x}$ \\
\hline 3 & $\begin{array}{l}\text { Accomplishing Much in a Short Time: Use of a Rapid Improvement Event to } \\
\text { Redesign the Assessment and Treatment of Patients With Alcohol Withdrawal }\end{array}$ & $\mathrm{x}$ \\
\hline 4 & $\begin{array}{l}\text { "Lean occupational" safety: An application for a Near-miss Management System } \\
\text { design }\end{array}$ & $\mathrm{x}$ \\
\hline 5 & $\begin{array}{l}\text { Reducing Door-to-Needle Times Using Toyota's Lean Manufacturing Principles } \\
\text { and Value Stream Analysis }\end{array}$ & 10 \\
\hline 6 & Exploring improvements in patient logistics in Dutch hospitals with a survey & 2 \\
\hline 7 & $\begin{array}{l}\begin{array}{l}\text { The Intersection of Evidence-Based Practice With } 5 \text { Quality Improvement } \\
\text { Methodologies }\end{array} \\
\end{array}$ & 7 \\
\hline 8 & SimLean: Utilising simulation in the implementation of lean in healthcare & 19 \\
\hline 9 & $\begin{array}{l}\text { Nurse-led liaison mental health service for older adults: Service development using } \\
\text { lean thinking methodology }\end{array}$ & 1 \\
\hline 10 & $\begin{array}{l}\text { Facilitating Lean Learning and Behaviors in Hospitals During the Early Stages of } \\
\text { Lean Implementation }\end{array}$ & 2 \\
\hline 11 & $\begin{array}{l}\text { Optimizing Clinical Operations as Part of a Global Emergency Medicine Initiative } \\
\text { in Kumasi, Ghana: Application of Lean Manufacturing Principals to Low-resource } \\
\text { Health Systems }\end{array}$ & 3 \\
\hline 12 & $\begin{array}{l}\text { Quality Initiatives Lean Approach to Improving Performance and Efficiency in a } \\
\text { Radiology Department }\end{array}$ & 15 \\
\hline 13 & Lean in healthcare: The unfilled promise? & 45 \\
\hline 14 & $\begin{array}{l}\text { Applying value stream mapping techniques to eliminate non-value-added waste for } \\
\text { the procurement of endovascular stents }\end{array}$ & 16 \\
\hline 15 & $\begin{array}{l}\text { Lean thinking transformation of the unsedated upper gastrointestinal endoscopy } \\
\text { pathway improves efficiency and is associated with high levels of patient } \\
\text { satisfaction }\end{array}$ & 5 \\
\hline 16 & $\begin{array}{l}\text { How to save costs by reducing unnecessary testing: Lean thinking in clinical } \\
\text { practice }\end{array}$ & 7 \\
\hline 17 & Applying lean six sigma to improve healthcare: An empirical study & \\
\hline 18 & Process Improve & 7 \\
\hline 19 & $\begin{array}{l}\text { Lean thinking: Can it improve the outcc } \\
\text { district general hospital? }\end{array}$ & 8 \\
\hline 20 & $\begin{array}{l}\text { Use of Lean and Six Sigma Methodology to Improve Operating Room Efficiency in } \\
\text { a High-Volume Tertiary-Care Academic Medical Center }\end{array}$ & 27 \\
\hline 21 & $\begin{array}{l}\text { Lean service operations: Reflections and new directions for capacity expansion in } \\
\text { outpatient clinics }\end{array}$ & 31 \\
\hline 22 & $\begin{array}{l}\text { Kaizen Method for Esophagectomy Patients: Improved Quality Control, Outcomes, } \\
\text { and Decreased Costs }\end{array}$ & 7 \\
\hline 23 & Lean Enablers for Systems Engineering & 33 \\
\hline 24 & $\begin{array}{l}\text { A Lean Laboratory Operational Simplicity and Cost Effectiveness of the Luminex } \\
x T A G(T M) \text { Respiratory Viral Panel }\end{array}$ & 14 \\
\hline 25 & $\begin{array}{l}\text { Exploring the relation between process design and efficiency in high-volume } \\
\text { cataract pathways from a lean thinking perspective }\end{array}$ & 6 \\
\hline 26 & Developing lean and agile health care supply chains & 25 \\
\hline 27 & $\begin{array}{l}\text { The role of actor associations in understanding the implementation of Lean } \\
\text { thinking in healthcare }\end{array}$ & 17 \\
\hline 28 & Fujitsu's Lean Solutions Group -Lean Healthcare in Canada & 1 \\
\hline 29 & Lean methodology in i.v. medication processes in a children's hospital & 4 \\
\hline 30 & Efficacy and efficiency of a lean cataract pathway: a comparative study & 7 \\
\hline
\end{tabular}




\begin{tabular}{|c|c|c|}
\hline Artigo & Título & $\begin{array}{c}\mathbf{N}^{\circ} \text { de } \\
\text { citações }\end{array}$ \\
\hline 31 & $\begin{array}{l}\text { Medication reconciliation in the emergency department: opportunities for } \\
\text { workflow redesign }\end{array}$ & 12 \\
\hline 32 & $\begin{array}{l}\text { Lean implementation in primary care health visiting services in National Health } \\
\text { Service UK }\end{array}$ & 18 \\
\hline 33 & Lean thinking in healthcare: a realist review of the literature & 75 \\
\hline 34 & Lean healthcare: Rhetoric, ritual and resistance & 48 \\
\hline 35 & $\begin{array}{l}\text { Quality in Trauma Care: Improving the Discharge Procedure of Patients by } \\
\text { Means of Lean Six Sigma }\end{array}$ & 21 \\
\hline 36 & Blood wastage reduction using Lean Sigma methodology & 12 \\
\hline 37 & $\begin{array}{l}\text { International benchmarking of specialty hospitals. A series of case studies on } \\
\text { comprehensive cancer centres }\end{array}$ & 10 \\
\hline 38 & Hospital capacity planning: from measuring stocks to modelling flows & 11 \\
\hline 39 & $\begin{array}{l}\text { Understanding waiting lists as the matching of surgical capacity to demand: are } \\
\text { we wasting enough surgical time? }\end{array}$ & 16 \\
\hline 40 & $\begin{array}{l}\text { Teaching Internal Medicine Residents Quality Improvement and Patient Safety: A } \\
\text { Lean Thinking Approach }\end{array}$ & 24 \\
\hline 41 & Mistake-proofing healthcare: Why stopping processes may be a good start & 6 \\
\hline 42 & $\begin{array}{l}\begin{array}{l}\text { Application of the Toyota Production System Improves Core Laboratory } \\
\text { Operations }\end{array} \\
\end{array}$ & 19 \\
\hline 43 & $\begin{array}{l}\text { Applying the Lean principles of the Toyota Production System to reduce wait times } \\
\text { in the emergency department }\end{array}$ & 40 \\
\hline 44 & $\begin{array}{l}\text { Effect of lean process improvement techniques on a university hospital inpatient } \\
\text { pharmacy }\end{array}$ & 12 \\
\hline 45 & Use of Lean in the Emergency Department: A Case Series of 4 Hospitals & 54 \\
\hline 46 & Writing The New Playbook For US Health Care: Lessons From Wisconsin & 28 \\
\hline 47 & $\begin{array}{l}\text { The Henry Ford Production System: LEAN Process Redesign Improves Service in } \\
\text { the Molecular Diagnostic Laboratory A Paper from the } 2008 \text { William Beaumont } \\
\text { Hospital Symposium on Molecular Pathology }\end{array}$ & 6 \\
\hline 48 & Making cars and making health care: a critical review & 20 \\
\hline 49 & Implementation of releasing time to care - the productive ward & 31 \\
\hline 50 & $\begin{array}{l}\text { Improving the efficiency of a chemotherapy day unit: Applying a business } \\
\text { approach to oncology }\end{array}$ & 23 \\
\hline 51 & Hospital government-conceptualization and instrumentation & $\mathrm{x}$ \\
\hline 52 & Lean Laboratories: Competing with Methods From Toyota & 5 \\
\hline 53 & A critical look at Lean Thinking in healthcare & 86 \\
\hline 54 & Reducing errors in the clinical laboratory: A lean production system approach & 5 \\
\hline 55 & $\begin{array}{l}\text { Streaming by case complexity: Evaluation of a model for emergency department } \\
\text { Fast Track }\end{array}$ & 34 \\
\hline 56 & $\begin{array}{l}\text { Redesigning care at the Flinders Medical Centre: clinical process redesign using } \\
\text { "lean thinking" }\end{array}$ & 62 \\
\hline 57 & Lean thinking across a hospital: redesigning care at the Flinders Medical Centre & 84 \\
\hline 58 & Lean health care: What can hospitals learn from a world-class automaker? & 123 \\
\hline 59 & From cars to catheters: Adapting lean principles within a healthcare environment & $\mathrm{x}$ \\
\hline 60 & $\begin{array}{l}\text { Lead-time reduction utilizing lean tools applied to healthcare: the inpatient } \\
\text { pharmacy at a local hospital }\end{array}$ & 16 \\
\hline 61 & $\begin{array}{l}\text { On the day of surgery: How long does preventable disruption prolong the patient } \\
\text { journey? }\end{array}$ & 4 \\
\hline 62 & Quality improvement: Theory and practice & 4 \\
\hline 63 & Getting 'Lean': hardwiring process excellence into Northeast Health & 8 \\
\hline 64 & Evaluating Lean in healthcare & $\mathrm{x}$ \\
\hline 65 & $\begin{array}{l}\text { Teaching workflow analysis and lean thinking via simulation: a formative } \\
\text { evaluation }\end{array}$ & 4 \\
\hline 66 & $\begin{array}{l}\text { Waste savings in patient transportation inside large hospitals using lean thinking } \\
\text { tools and logistic solutions }\end{array}$ & $\mathrm{x}$ \\
\hline 67 & Outsourcing in healthcare through process modularization- A lean perspective & $\mathrm{x}$ \\
\hline 68 & Measuring lean initiatives in health care services: Issues and findings & 102 \\
\hline
\end{tabular}




\begin{tabular}{c|l|c}
\hline Artigo & \multicolumn{1}{|c|}{ Título } & $\begin{array}{c}\text { No de } \\
\text { citações }\end{array}$ \\
\hline 69 & $\begin{array}{l}\text { How does lean work in emergency care? A case study of a lean-inspired } \\
\text { intervention at the Astrid Lindgren Children's hospital, Stockholm, Sweden }\end{array}$ & 11 \\
\hline 70 & The "control tower" approach to optimising complex service delivery performance & $\mathrm{x}$ \\
\hline 71 & $\begin{array}{l}\text { Implementing large-scale quality improvement: Lessons from The Productive } \\
\text { Ward: Releasing Time to Care }\end{array}$ & 6 \\
\hline 72 & $\begin{array}{l}\text { Continuous improvement and dynamic actor associations: A study of lean thinking } \\
\text { implementation in the UK National Health Service }\end{array}$ & 6 \\
\hline 73 & $\begin{array}{l}\text { Thinking lean: implementing DMAIC methods to improve efficiency within a cystic } \\
\text { fibrosis clinic }\end{array}$ & 7 \\
\hline 74 & Applying lean techniques to improve the patient scheduling process & 16 \\
\hline
\end{tabular}

Já a terceira análise, buscou identificar a quantidade de artigos por ano. Como é possível analisar na Figura 2, mesmo não havendo filtro referente ao ano, as publicações começaram a partir de 2006. Com relação a maior concentração dos artigos, estes se encontram nos anos de 2010 e 2012 com 17 e 16 artigos respectivamente.

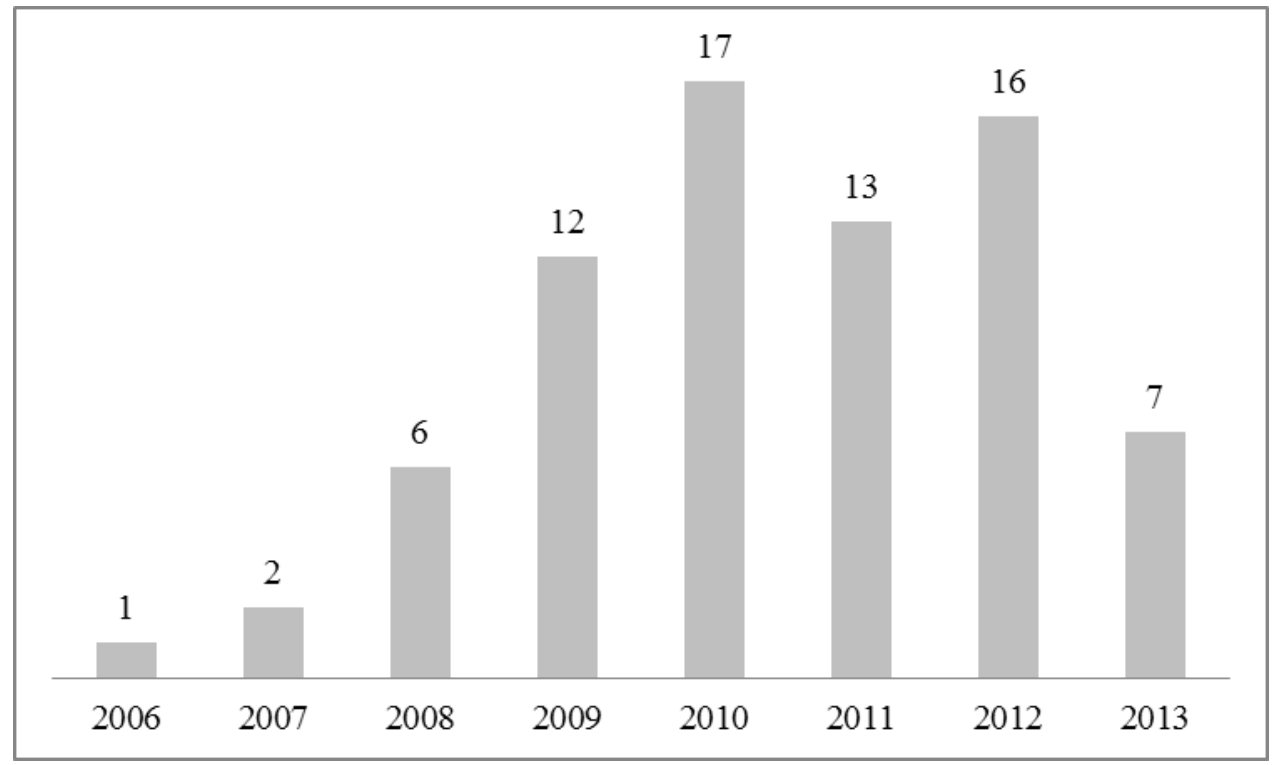

Figura 2 - Quantidade de artigos por ano

\subsection{Análise de conteúdo}

Após a leitura completa dos 74 artigos do portfólio, mais 13 trabalhos foram retirados do portfólio por não apresentarem o que o estudo em questão buscava. Sendo assim, ficaram 61 artigos, com base nos dados levantados neles, foi criada a Tabela $4 \mathrm{com}$ a finalidade de sumarizar as principais contribuições dos artigos.

Tabela 4 - Resultado dos 61 documentos pesquisados

Artigos

\section{Artigo 1}

Objetivo - Avaliar a eficácia dos princípios Lean no primeiro caso da sala de operação e os efeitos quantificados sobre as horas de trabalho residentes

Conclusão - O uso de princípios de Lean permitiu a rápida identificação e implementação de mudanças no processo perioperatório que melhoraram a eficiência e resultaram em significativa redução de custos

\section{Artigo 2}

Objetivo - Ilustrar a aplicação do A3 Problem Solving Reports do Sistema Toyota de Produção

Conclusão - Resultados positivos para ambos os relatórios foram obtidos e validados por planos de auditoria 


\section{Artigos}

robustas

Artigo 3

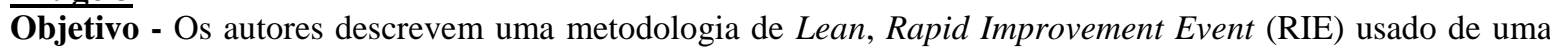
forma única para desenvolver um novo protocolo de tratamento para uma condição médica específica: abstinência do álcool

Conclusão - O RIE permitiu a colaboração de um grupo multidisciplinar de provedores que investiram no sucesso de um novo protocolo para a retirada do álcool que se estende por áreas do departamento de emergência para a ala de. Permitiu também a definição de medidas para o seu sucesso, uma vez que é implementado

\section{Artigo 4}

Objetivo - Utilizar a metodologia de melhoria do processo Lean para desenvolver um protocolo de tPA intravenosa aerodinâmico

Conclusão - Princípios de manufatura enxuta foram aplicados para agilizar a entrega tPA intravenosa com dramática redução DNTs e sem comprometer a segurança do paciente. Estudos futuros poderão determinar se essa intervenção é sustentável em vários ambientes hospitalares

\section{Artigo 5}

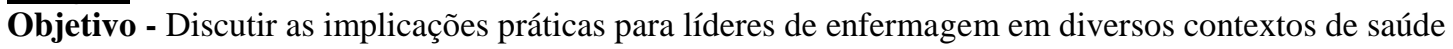

Conclusão - Os autores descrevem a intersecção de várias metodologias de melhoria da qualidade, com o processo de prática baseada em evidências. Cinco abordagens de melhoria da qualidade, plan-do-check-act, Six Sigma, Lean, análise de causa raiz e análise de efeitos do modo de falha, são descritos e são usadas para enquadrar exemplos

\section{$\underline{\text { Artigo 6 }}$}

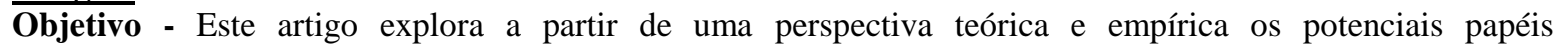
complementares de DES e Lean na área da saúde. O objetivo é aumentar o impacto de ambas as abordagens na melhoria dos sistemas de saúde

Conclusão - O trabalho demonstra como a fusão de DES com Lean pode melhorar tanto a participação dos interessados com DES e do impacto do Lean

\section{Artigo 7}

Objetivo - Descrever a melhoria e desenvolvimento de um serviço de ligação para os adultos mais velhos, baseado no Sistema Toyota de Produção, para melhorar o acesso aos serviços de saúde mental para pacientes medicamente doentes mais velhos e melhorar o seu atendimento global

Conclusão - Resultou na melhoria do acesso aos serviços de saúde mental para idosos internados clinicamente doentes e melhoria da qualidade de seus cuidados em geral

\section{$\underline{\text { Artigo } 8}$}

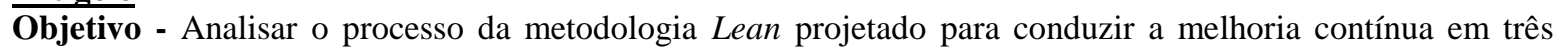
hospitais rurais com foco em profissionais de saúde envolvidos no esforço como participantes Lean

Conclusão - Insights e recomendações para facilitar o pensamento e comportamentos Lean durante os primeiros anos de execução do programa Lean são fornecidos

\section{Artigo 9}

Objetivo - Descrever a aplicação de técnicas de Manufatura Enxuta (ME) para melhorar as operações clínicas no Komfo Anokye Teaching Hospital (KATH) em Gana e identificar as principais lições aprendidas para ajudar futuras iniciativas ME global

Conclusão - Os autores identificaram oito lições aprendidas durante o uso do Lean para otimizar as operações em um ambiente global de saúde : 1) o processo de Lean auxiliado na construção de uma parceria com colegas de Gana ,2) a obtenção e manutenção de apoio institucional sênior é necessário e desafiador ; 3) sobre as diferenças de poder entre a equipe para obter feedback de todos os membros da equipe é fundamental para uma análise sucesso, 4) a escolha de um projeto inicial gerenciável é fundamental para influenciar o uso de Lean a longo prazo em um ambiente novo ; 5) dados intensivos ferramentas Lean podem ser adaptados e são eficazes em um sistema de saúde menos recursos suficientes; 6) várias ferramentas Lean focado na equipe de técnicas de resolução de problemas funcionou bem em um sistema de baixos recursos, sem modificação ; 7) usando o Lean destacou que importantes mudanças não exigem um influxo de recursos , e 8 ), apesar de diferentes níveis de recursos, causas da ineficiência do sistema são muitas vezes semelhantes em todos os sistemas de cuidados de saúde, mas exigem soluções únicas apropriadas para o ambiente clínico

\section{$\underline{\text { Artigo } 10}$}

Objetivo - Descrever os princípios e ferramentas da abordagem Lean codificados no Sistema Toyota de Produção básicos e mostra como esses princípios e ferramentas podem ser aplicadas às operações de radiologia 


\section{Artigos}

Conclusão - A implementação de uma abordagem enxuta para melhorar o desempenho organizacional implica nunca perder de vista o que o cliente quer, o objetivo, ou o ideal. Como acontece com todos esses esforços, independentemente da abordagem, a transformação Lean é um processo que começa com um único passo e requer um compromisso contínuo por todos os membros da equipe. O envolvimento de todos é encorajado, e suas contribuições são respeitados. Os autores esperam que os leitores sejam inspirados a levar esse único passo em frente e começar a trabalhar com sua própria liderança departamental, gestão e pessoal para aplicar os princípios Lean para melhorar a eficiência, desempenho, segurança e comprometimento dos funcionários

\section{Artigo 11}

Objetivo - Examinar uma intervenção Lean inspirado em um acidente pediátrico sueco no departamento de emergência

Conclusão - Adicionar um novo conhecimento a respeito de como os princípios Lean podem ser beneficamente aplicados na área da saúde e identifica alterações em funções profissionais como um desafio potencial ao introduzir pensamento enxuto. Esse conhecimento pode permitir que as organizações de saúde e gestores de outras definições para configurar seu próprio programa Lean e para melhor compreender as razões do sucesso ou fracasso do Lean

Artigo 12
Objetivo - Relatar em quatro estudos de caso multi-nível da implementação do Lean no NHS inglês
Conclusão - Lean é um conceito poderoso para a melhoria de processos, e, sem dúvida, tem muito para
oferecer para as operações de saúde e o setor público em geral. No entanto, como os resultados mostram que
Lean é realmente dependente do contexto, embora não no sentido comumente assumido: a percepção de que o
Lean é um conceito de fabricação que é difícil de aplicar em um contexto de serviço está claramente errada. O
futuro do Lean na área da saúde é desenvolver sistemas que garantam que os investimentos existentes em
Lean é sustentado, enquanto seus pressupostos subjacentes são reconhecidos, mentalidades e estruturas. A fim
de derivar os benefícios do Lean, em qualquer contexto, não há simplesmente nenhum atalho para
compreender seus princípios fundamentais e pressupostos subjacentes

\section{$\underline{\text { Artigo } 13}$}

Objetivo - Eliminar não-agregação de valor (NVA) resíduos para a aquisição de endopróteses endovasculares em serviços de radiologia intervencionista, aplicando o mapeamento do fluxo de valor (VSM).

Conclusão - VSM é uma ferramenta de visualização para o abastecimento da cadeia e valor fluxo, baseado no Sistema Toyota de Produção e auxilia grandemente na implementação com sucesso um sistema enxuto

\section{Artigo 14}

Objetivo - O objetivo deste estudo foi redesenhar esta via para pacientes sedado usando a transformação de pensamento enxuto para focar o paciente-derivado, remover desperdícios e criar um processo mais eficiente. Isto foi para formar a base de um modelo de caminho que era transferível para outras unidades de endoscopia

Conclusão - Lean transformação de endoscopia UGI resultados de percurso em reduzido tempo de espera, reduzido requisitos de pessoal e melhorou o fluxo de pacientes e pode se formar a base de um modelo de caminho que pode ser transformado com êxito em ambientes alternativos endoscopia com altos níveis de satisfação do paciente

\section{$\underline{\text { Artigo } 15}$}

Objetivo - Este estudo propõe a combinação sinérgica de Lean e SS para melhoria de processos e qualidade. Destina-se a aplicar a metodologia LSS integrada para melhorar a eficiência do processo de D2B. A justificativa para combinar as duas disciplinas também é examinada e justificada por uma base teórica

Conclusão - Os resultados do estudo indicam que o LSS não só melhorou qualidade médica, mas também reforço da competitividade

\section{Artigo 16}

Objetivo - Este trabalho visa desenvolver um quadro conceitual unificador e quantitativo para processos de saúde do ponto de vista da melhoria de processos. O trabalho se adapta modelos padrão de gestão de operação para as especificidades dos processos de saúde

Conclusão - Os links de metodologia proposta sobre a metodologias de melhoria de processos, tais como reengenharia de processos, seis sigmas, pensamento enxuto, teoria das restrições e gestão da qualidade total. Fornecendo modelos conceituais e modelos práticos para diagnóstico do processo, o quadro se relaciona muitas vertentes desconectadas de pesquisa e aplicação em melhoria de processos na área da saúde na busca unificadora de melhoria de processos

\section{Artigo 17}


abordagem fluxo de valor, a estrutura Lean, em nossa confiança. Este sistema utiliza os recursos disponíveis de forma eficiente, enquanto eliminando o desperdício

Conclusão - Este é o maior estudo na literatura onde a estrutura Lean tem sido empregada com sucesso para a 


\section{Artigos}

gestão de um problema de saúde muito desafiadores enfrentado pelo serviço nacional de saúde. Futuros estudos prospectivos são, no entanto, necessários para confirmar estes resultados e avaliar os componentes que são mais críticos para o sucesso do quadro implementado

\section{Artigo 18}

Objetivo - Aplicar metodologias Lean e Seis Sigmas com um todo pacote cirúrgico para melhorar a eficiência Conclusão - A utilização de metodologias Lean e Seis Sigmas aumentou eficiência e desempenho financeiro das salas de operações (OR) com um todo pacote de funcionamento. Mapeamento de processos, suporte a liderança, compromisso pessoal e compartilhamento de métricas de desempenho são as chaves para melhorar a eficiência de OR. Os ganhos de desempenho foram positivos, substancial e sustentável financeiramente e transferíveis para outras especialidades

\section{Artigo 19}

Objetivo - Esta pesquisa de campo em operações de serviço ambulatorial examina os originais dados quantitativos sobre as nomeações e analisa um projeto de melhoria de processo Lean que foi conduzido para aumentar a capacidade de admitir novos pacientes em um sistema de operação de serviço de saúde

Conclusão - O estudo gera insights sobre alinhamento eficaz dos recursos, desenvolve novas estratégias para operações de serviço responder a comparências, revela as variáveis relacionadas ao tempo que tem sido negligenciada em agendamento de pesquisa e os desafios tradicional OM agendamento de desempenho mede

\section{Artigo 20}

Objetivo - A maioria dos custos associados à Esofagectomia está relacionada com os iniciais 3 dias de internação hospitalar que requerem tempo intra-operatório, assistência de um ventilador e estadias de unidade de terapia intensiva. Os custos adicionais decorrem de serviços hospitalares. Os aumentos de custos principais estão relacionados com as complicações associadas com o procedimento. Buscou-se definir estes custos e identificar a gestão de despesas pela racionalização cuidados através da aderência estrita aos mapas de atendimento ao paciente, padronização decisória e rápida descarga de planejamento para reduzir a variabilidade

Conclusão - Utilizando técnicas de manufatura enxuta e avaliação de processo contínuo, tentamos eliminar variabilidade, padronizou as fases dos cuidados, resultando em melhores resultados, diminuição da duração da estadia e melhorou as margens de contribuição. Estas melhorias Kaizen requerem intervenções contínuas, aderência estrita aos mapas de cuidados e entrada de todos os níveis para melhorias de qualidade

\section{Artigo 21}

Objetivo - Implementar os princípios da análise de fluxo de trabalho operacional, utilizando a metodologia Lean para avaliar criticamente as vantagens potenciais de um multiplexado RT-PCR ensaio tanto em termos de fluxo de trabalho e custo eficácia

Conclusão - Resultados indicaram que a implementação do Luminex xTAG painel Viral respiratória (RVP) resultou em um fluxo de trabalho padronizado com diminuiu requisitos no custo de laboratório, bem como a melhoria na eficiência

\section{Artigo 22}

Objetivo - Comparar modelos de processo de três vias de alto volume de catarata em um quadro de pensamento enxuto e explorar como eficiência em termos de prazos, hospital visitas e custa está relacionado ao processo de design

Conclusão - Foco operacional foi influenciado por circunstâncias externas, levando a diferentes orientações sobre a eficiência. Puxe o planejamento com a integração de atividades em uma paragem procedimentos realizados por enfermeiros polivalentes, bem como eliminar desperdícios reduzidos tanto o número de visitas do hospital e os custos. Prazos curtos foram associados com o uso de um ambulatório geral e de uma clínica de cirurgia de catarata de alto volume

\section{Artigo 23}

Objetivo - O objetivo deste trabalho exploratório é descobrir o que é importante considerar ao desenvolver uma cadeia de suprimentos em saúde, o que é necessário para estabelecer uma orientação de cadeia de abastecimento e como Lean e ágeis podem ser usados como estratégias de processo a fim de melhorar o desempenho da cadeia de abastecimento

Conclusão - Gestão da cadeia de abastecimento tem potencial para funcionar bem como uma filosofia para o fluxo de pacientes no setor dos cuidados de saúde. No entanto, não será sobre o uso do conceito de Lean na área da saúde, como de fato é o caso na prática hoje. É um pouco sobre a organização para uma resposta rápida e flexibilidade em uma estratégia híbrida através de combinando estratégias de processo enxuto e ágil. Isto só pode ser feito se uma abordagem de sistemas é aplicada em conjunto com uma orientação estratégica, onde os esforços de cooperação pelos membros da cadeia de abastecimento devem sincronizar e convergir recursos operacionais, bem como estratégicos para uma unificação inteira 


\section{Artigos}

Objetivo - Explorar a dinâmica na implementação de uma metodologia de melhoria de processo no cenário organizacional complexa de um UK National Health Service Trust

Conclusão - ANT é útil para rastrear explicitamente como os jogadores organizacionais mudam suas posições e alianças de rede ao longo do tempo, e para a identificação de objetos e ações que sejam eficazes no envolvimento indivíduos em redes que permitem a transição para um processo Lean. É importante para atender a dinâmica do processo de mudança e elaborar intervenções oportunas apropriadas permitindo que os intervenientes a mudar suas posições no sentido de um resultado desejado

\section{Artigo 25}

Objetivo - Apresentar exemplo de navegação baseada o Lean Healthcare praticada por grupo de soluções Lean Fujitsu Fujitsu Consulting

Conclusão - Lean Healthcare estabeleceu prática recomendada de classe mundial que tem potencial para ser uma vantagem estratégica e competitiva de mercado para resolver a crise no setor da saúde, fornecendo qualidade e serviços oportunos para pacientes de baixo custam, bem como fornecendo mais ambientes de trabalho eficiente e melhor para os médicos e funcionários.

\section{Artigo 26}

Objetivo - Estudar o impacto da metodologia Lean em processos de medicação intravenosa em um hospital infantil

Conclusão - Aplicação de conceitos Lean no processo de preparação de medicação intravenosa teve um efeito positivo na eficiência e custo de drogas

\section{Artigo 27}

Objetivo - Analisar a eficácia e a eficiência de um caminho de catarata Lean

Conclusão - Implicações práticas, via Lean podem realizar grandes melhorias e ainda tem uma lacuna significativa entre o atendimento esperado e o real. $\mathrm{O}$ desafio para as equipes de saúde não é melhorar a prestação de cuidados, usando caminhos Lean em vez de usar caminhos tradicionais

\section{Artigo 28}

Objetivo - Examinar o papel do redesenho de fluxo de trabalho para melhorar a conciliação de medicação em quatro departamentos de emergência comunitária do estado de Washington

Conclusão - Ideias para um fluxo de trabalho ideal para gerar uma lista de medicamentos incluem envolvimento de pacientes e utilizando empregados em maior medida na informação de medicação, coleta, identificação e sinalização de pacientes com falta de informação de medicamentos e recolhendo apenas a informação de medicação necessária para tomar decisões clínicas no departamento de emergência

\section{Artigo 29}

Objetivo - Este apresenta as conclusões de uma implementação enxuta de 13 meses em serviço de saúde de cuidados primários (NHS) de maio de 2008 a junho de 2009

Conclusão - Lean foi escolhido para este estudo, por causa de seu sucesso relatado em outras organizações de saúde. Mapeamento do fluxo de valor foi utilizado para mapear as tarefas essenciais para o serviço de visitas de saúde participantes. Mapeamento de stakeholders foi conduzido para determinar as ligações entre todas as partes interessadas. Processos de desperdícios foram então identificados através de discussões com essas partes interessadas, e foi produzido um mapa de processo redesenhado do estado futuro. Dados quantitativos foram fornecidos através de um estudo de tempo 10-dia de um número selecionado de funcionários dentro do serviço. Isto foi analisado para fornecer uma indicação da atividade de resíduos pode ser removida do sistema após melhorias planejadas

\section{Artigo 30}

Objetivo - Compreender como o pensamento enxuto tem sido posto em prática em cuidados de saúde e como tem funcionado

Conclusão - Os autores analisaram 33 artigos e descobriram uma vasta gama de aplicações do Lean. Os artigos descrevem as fases iniciais da implementação e sublinhar os aspectos técnicos. Todos os artigos relatam resultados positivos. Os autores encontraram aspectos contextuais comuns que interagem com diferentes componentes das intervenções Lean e acionam quatro diferentes mecanismos: compreender processos para gerar conhecimento compartilhado; organizar e projetar para eficácia e eficiência; melhorar a detecção de erros para aumentar a consciência e a confiabilidade do processo; e colaborar para sistematicamente resolver problemas para realçar a melhoria contínua

\section{Artigo 31}

Objetivo - Apresenta um relato etnográfico da implementação de metodologias de redesenho Lean de serviço em um hospital do NHS UK departamento de funcionamento

Conclusão - O artigo conclui que Lean pode não ser fácil para fazer tanta eficiência e a melhoria da eficácia na área da saúde 


\section{Artigo 32}

Objetivo - Em 2006 e 2007, a Universidade Medical Center Groningen nem sempre foi capaz de admitir todos os pacientes de trauma para o TND devido à ocupação relativamente alta-cama. Portanto, a redução do comprimento médio de estadia (LOS) formou o objetivo do projeto descrito neste estudo

Conclusão - O estudo mostra que o Lean Seis Sigma é um método eficaz para reduzir internação inadequada, melhorando assim a qualidade e a eficiência financeira de atendimento

\section{Artigo 33 \\ Objetivo - Utilizar Metodologia Lean Sigma como uma ferramenta para reduzir o desperdício de produto de $\mathrm{RBC}$, com foco no desperdício de contêiner, que estava determinado a produzir o maior impacto. Usando o processo de Lean Sigma cinco partes — definir, medir, analisar, melhorar e controlar — a equipe coletou dados de desperdício de linha de base, identificou os principais fatores que afetam o desperdício do produto RBC e implementadas intervenções para reduzir a quantidade de desperdício \\ Conclusão - A metodologia Lean Sigma foi uma ferramenta eficaz para reduzir o desperdício de RBC em um grande hospital universitário}

\section{Artigo 34}

Objetivo - Propor usando abordagens que são baseadas na teoria de fabricação, tais como "pensamento enxuto" que incide sobre o valor que diferentes processos adicionam para o cliente principal, ou seja, o paciente

Conclusão - Pode-se argumentar que é benéfico olhar para o hospital, não do ponto de vista de camas ou especialidades, mas sim do caminho percorrido pelos pacientes que são tratados, os respectivos processos entregues pelos profissionais de saúde e as instalações adequadas para esses processos. Caminhos de cuidados sistematizado parecem oferecer uma avenida para alcançar esses objetivos. No entanto, eles precisam ser sustentados por uma melhor compreensão dos fluxos de pacientes, trabalho e bens dentro de um hospital, os gargalos que ocorrem e tradução deste entendimento em novas ferramentas de planejamento de capacidade

\section{Artigo 35}

Objetivo - Duas preocupações significativas na área da saúde estão em espiral, custos e erros médicos. Estas duas preocupações são correlacionadas: eliminar erros médicos leva a reduções de custo significativas. Este artigo forneceu um exemplo, ThedaCare Inc., onde os dois problemas são melhorados, fornecendo mecanismos para os processos de saúde

Conclusão - Os resultados preliminares alcançados em cuidados de Theda demonstram os avanços médicos e financeiros que podem ser obtidos utilizando esses métodos

\section{Artigo 36}

Objetivo - Para atender às demandas clínicas aumentadas da nossa expansão de hospital, melhorar a qualidade e reduzir os custos, nossos cuidados terciários, laboratório núcleo pediátrica usado o processamento de Sistema Toyota de Produção Enxuto para reorganizar o nosso laboratório de núcleo de 7D/wk de 24 horas

Conclusão - O projeto teve a consequência imprevista eliminando STAT teste porque nosso TAT em laboratório para testes de rotina foi menor do que o nosso objetivo de reviravolta STAT prévia. A viabilidade dessa abordagem é demonstrada pelo sustentada ganhos e novas melhorias de PDCA (plano, Do, Check, Act) durante os 4 anos após a conclusão do projeto

\section{Artigo 37}

Objetivo - Avaliar o efeito de melhoria de processos Lean em uma farmácia hospitalar de internamento da universidade

Conclusão - Metodologia Lean foi implementada com sucesso na área de SPA e inventário na farmácia UMMC, Fairview, em regime de internamento. Benefícios desse processo incluem um custo anual estimada economia de US \$289.256 devido à redução de desperdícios, melhorias no fluxo de trabalho e diminuiu os requisitos de recrutamento

\section{Artigo 38}

Objetivo - Descrever os efeitos de uma estratégia de melhoria de processo pioneira pela Toyota o Lean, qualidade do atendimento em 4 departamentos de emergência (EDs)

Conclusão - Princípios Lean adaptados à cultura local de atendimento podem levar a mudanças de comportamento e melhorias sustentáveis na qualidade de métricas de cuidados no ED. Estas melhorias não são universais e são afetadas pela liderança e engajamento da força de trabalho da linha de frente

\section{Artigo 39}

Objetivo - Estudos ThedaCare conta processos de entrega para melhorar o atendimento e reduzir custos Conclusão - Lições de manufatura enxuta e o Instituto para a melhoria de cuidados de saúde estão reduzindo a incidência de nascimentos pré-termo, melhorando as taxas de resposta de ataque cardíaco, e o cuidado de forma a mudar é entregue em hospitais para uma abordagem colaborativa, baseada em equipe

\section{Artigo 40}




\section{Artigos}

Objetivo - Descrever os esforços para melhorar tempos de resposta de teste molecular, concentrando-se principalmente sobre o redesenho de processos, utilizando os princípios da produção enxuta. O objetivo era completar maior que $90 \%$ dos testes moleculares em menos de 3 dias

Conclusão - O processo de Lean resultou em menos etapas, aproximando-se o ideal de um fluxo de uma peça para amostras através de recolha/recuperação, transporte e os diferentes aspectos do processo de teste. $\mathrm{O}$ resultado da introdução do processo Lean foi uma redução de $44 \%$ no tempo de retorno do teste molecular para amostras de tecido, de uma média de 2,7 a 1,5 dias. Além disso, estender princípios de trabalho Lean para os fornecedores de médico resultou em um número consideravelmente maior de espécimes de sangue adequadamente coletados e enviados (de 50 a 87\%). Estas melhorias contínuas de qualidade foram realizadas por trabalhadores capacitados em um ambiente livre de culpa e agora estão sendo sustentadas com envolvimento mínimo de gerenciamento

\section{Artigo 41}

Objetivo - Este artigo descreve a implementação do NHS Institute for Innovation and Improvement Productive Ward - liberando tempo para programa de cuidados. Ele irá discutir os benefícios e principais sucessos e fornece conselhos para aqueles que desejam implementar o programa

Conclusão - Programa melhora a satisfação do paciente, como permite a prestação de um aumento no atendimento direto ao paciente pela equipe de funcionários e posteriormente melhorado clínico e resultados de segurança. Inclui a liderança, gerenciamento de projetos e técnicas de metodologia Lean

\section{Artigo 42}

Objetivo - Melhorar a eficiência de uma unidade de dia de quimioterapia baseada em hospital (CDU)

Conclusão - O método usado melhorou o processo de design e levou ao aumento da eficiência e uma entrega mais oportuna de cuidados. Assim, as abordagens de negócios, que foram adaptadas para cuidados de saúde, foram aplicadas com êxito. O método pode servir de exemplo para outras configurações de Oncologia com problemas relativos a tempos de espera, o fluxo de pacientes ou falta de camas

\section{Artigo 43}

Objetivo - O hospital evolui de um sistema arcaico, para um moderno, propomos para destacar a benefícios da escola Lean de administração da empresa, que analisa o desempenho, visto a partir de dois perspectivas - de produtividade e qualidade - através da melhoria contínua e reduzindo perdas

Conclusão - Adaptação gestão Lean para o ambiente hospitalar traz uma metodologia impecável que: Permite que a descrição da instituição no contexto ou fornecer os meios e análise métodos do ambiente, dos pareceres internos e externos. - Torna possível a descrição do eixo principal de desenvolvimento, os objectivos associados cada nível de responsabilidade, utilizando o método de recolha dos factos referindo-se a atividade e os meios fornecidos pela lista de possibilidades internas e externas. - Facilita a busca, em todos os níveis, dos processos de melhoria contínua, contando com a conhecimento e experiência dos profissionais, que facilitam as tarefas diárias

\section{Artigo 44}

Objetivo - Apresentar que o Lean pode defender e proteger o emprego para o laboratório, ao mesmo tempo melhorar tempos de resposta e serviço para os pacientes e reduzindo os custos para o hospital

Conclusão - Método Lean proporciona aos laboratórios e seus colaboradores uma forma de garantir que os pacientes e médicos ficarão satisfeitos com a qualidade e o serviço prestado pelo laboratório. Muitos laboratórios na América do Norte têm aproveitado para a criatividade dos seus empregados para redesenhar layouts e processos de uma forma que melhor atende pacientes e melhora a satisfação do paciente

\section{$\underline{\text { Artigo } 45}$}

Objetivo - Fornecer uma análise preliminar das áreas onde a interpolação de outros setores de cuidados de saúde é relativamente bem compreendida, baseado em uma ampla revisão de seu impacto no atendimento. Propõe ainda áreas onde o desenvolvimento conceitual é necessário. Em particular, cuidados de saúde, com suas muitas medidas de valor, apresenta um desafio incomum ao condutor central Lean de valor para o cliente Conclusão - Conclui-se que há espaço para o desenvolvimento metodológico, talvez definindo três temas associados com valor - o operacional, o clínico e o experiencial

\section{Artigo 46}

Objetivo - Para avaliar um paciente fluxo sistema de streaming dentro de ED de um hospital-escola, usando princípios funcionais para separar os pacientes em dois fluxos com base na complexidade ao invés de acuidade, severidade ou disposição

Conclusão - O projeto usado princípios conceituais, tais como a complexidade paciente e 'pensamento enxuto' teoria, para criar um novo fluxo paciente de Fast Track, que era separadamente dos recursos adequado. Após a implementação do sistema, melhorias significativas foram observadas em vários indicadores de desempenho chave. 


\section{Artigos}

\section{Artigo 47}

Objetivo - O Centro Médico Flinders (FMC) redesenhando programa começou em novembro de 2003; é um programa de melhoria de processo de todo o hospital aplicando uma abordagem denominada "pensamento enxuto" (desenvolvido no setor da manufatura) aos cuidados de saúde. • Até à data, a FMC envolveu centenas de funcionários de todas as áreas do hospital, em uma grande variedade de atividades de redesenho de processo. - O foco inicial do programa era sobre a melhoria do fluxo de pacientes, através do departamento de emergência, mas o programa rapidamente se espalhou para envolver o redesenho de gestão médicos e cirúrgicos de pacientes em todo o hospital e para melhorar os serviços de apoio

Conclusão - Resultados até à data mostram que o programa redesenhando permitiu que o hospital fornecesse mais seguras e acessíveis o cuidado durante um período de crescimento da demanda

\section{$\underline{\text { Artigo } 48}$}

Objetivo - Documenta a introdução e desenvolvimento de cuidados de redesenhar, um programa baseado no pensamento Lean para redesenhar processos de cuidados em um hospital geral universitário

Conclusão - Redesenhar cuidados produziu benefícios substanciais durante os primeiros anos da dois-e-ummetade da sua aplicação, tornando o cuidado mais seguro e mais acessível. Redesenhar cuidados tem não sido destinada a alterar as especificidades da prática clínica. Em vez disso, ele tem se preocupado com melhoria do fluxo de pacientes através de sistemas clínicos e outros. Conceitos que surgiram no setor industrial foram facilmente traduzíveis em cuidados de saúde. Pensamento enxuto pode desempenhar um papel importante na reforma dos cuidados de saúde na Austrália e em outros lugares

\section{Artigo 49}

Objetivo - Descreve alguns conceitos da filosofia básica e princípios de métodos de produção enxuta e como esses conceitos podem ser aplicados no ambiente de cuidados de saúde. É descrito algumas histórias de sucesso precoce e esforços em curso de produção enxuta em várias organizações de cuidados de saúde. Acreditamos que o hospital é o cenário ideal para o uso do método de produção enxuta, que poderia afetar significativamente como cuidados de saúde é entregue aos pacientes

Conclusão - Concluíram discutindo alguns dos desafios potenciais na introdução e implementação de métodos de produção enxuta no ambiente de cuidados de saúde. Produção enxuta é uma nova abordagem para o fornecimento de cuidados de alta qualidade e eficiente aos pacientes, e acreditamos que o setor de cuidados de saúde pode antecipar o mesmo nível de sucesso que alcançaram a fabricação e indústrias de serviços usando esta abordagem.

\section{Artigo 50}

Objetivo - Este fornece como a adaptação do Sistema Toyota de Produção ajudou a transformar um hospital francês em um ambiente de aprendizagem. Além de detalhar sobre a aplicação de vários princípios Lean fundamentais, algumas das dificuldades encontradas e as melhorias que resultou. $\mathrm{O}$ artigo contém muitas implicações estratégicas importantes que dizem respeito não só para um ambiente de cuidados de saúde, mas também para uma aplicação mais ampla do pensamento enxuto

Conclusão - A primeira vista, parece absurda qualquer comparação entre um automóvel e uma ala do hospital. Mas tal suposição acha sem o renomado Sistema Toyota Produção (TPS) que está se tornando cada vez mais comuns em ambientes fora da indústria automotiva. Pensamento enxuto é o cerne do TPS e essa filosofia tem influenciado a cultura do local de trabalho no hospital Nord 92 na periferia de Paris, a capital francesa. Gerência e os funcionários têm implementado magros princípios-chave para criar um ambiente de aprendizagem, agora muito melhor equipado para melhorar e crescer

\section{Artigo 51}

Objetivo - Aplicar selecionados princípios de gestão enxuta visando reduzir o desperdício de tempo associado a uma farmácia de internação em um hospital local de distribuição de drogas

Conclusão - Os resultados obtidos com o estudo revelaram o potencial de poupança de > 45\% na droga dispensando o tempo de ciclo

\section{Artigo 52}

Objetivo - Este artigo enfoca a abordagem utilizada pelo Northeast Health e introduzir conceitos Lean na sua cultura, desafios, lições aprendidas e os fatores críticos para o sucesso

Conclusão - Introduziu o conceito Lean em sua cultura, em 2004. Depois de quatro anos, a organização está começando a ver o pensamento Lean no comportamento do dia a dia de seus funcionários

\section{Artigo 53}

Objetivo - Apresentar as conclusões relativas a como Lean é implementado em hospitais inglês

Conclusão - O artigo identifica abordagens divergentes para implementação enxuta nos hospitais ingleses. Essas abordagens são classificadas em uma tipologia para facilitar uma avaliação de como Lean é implementado. Os resultados sugerem que a aplicação tende a ser isolado ao invés de todo o sistema. Um segundo conjunto de dados transmite a trajetória de implementação de Lean em todo o período de tempo. 


\section{Artigos}

Estes dados sinalizaram crescente uso do Lean por progressão de hospitais e programas de Inglês para uma abordagem sistêmica cada vez mais

\section{Artigo 54}

Objetivo - Este artigo apresenta a justificativa para a concepção e o desenvolvimento de uma simulação de vídeo para ensinar análise de pensamento enxuto de fluxo de trabalho para gerenciamento de informações de saúde e serviços de saúde a estudantes matriculados em um curso sobre o gerenciamento de informações de saúde

Conclusão - Baseado nos resultados de uma pesquisa dada aos 75 estudantes como parte da avaliação formativa, a simulação de vídeo foi julgada eficaz porque permitiu que os alunos a visualizar o processo do mundo real (experiência concreta), contemplar as cenas retratadas no vídeo junto com os conceitos apresentados em classe em um ambiente livre de risco (reflexão), desenvolver hipóteses sobre por que os problemas ocorridos no processo de fluxo de trabalho (conceituação abstrata)e desenvolver soluções para reformular os processos selecionados (experimentação ativa)

\section{Artigo 55}

Objetivo - O artigo lida com a questão do transporte de pacientes dentro de hospitais públicos de grande porte e seus custos. Este custo é muitas vezes relacionado com transporte dentro de departamentos, enfermarias e clínicas de ambulatório. O objetivo deste trabalho é demonstrar através de um estudo de caso qualitativo ferramentas como particulares, derivadas de Lean Thinking como gráfico de espaguete, mapeamento do fluxo de valor e planilha de atividade pode ajudar a reduzir os custos relacionados com o transporte de pacientes e outros tipos de resíduos. Em particular, o estudo de caso analisa o caminho paciente em caso de trauma com suspeitas fraturas do departamento de emergência à paciente descarga ou hospitalização

Conclusão - O artigo demonstra como ferramentas que eram tipicamente derivadas do setor manufatureiro também podem ser apropriadas para o setor da saúde. Os resultados obtidos reduziram o prazo médio de execução do paciente do departamento de emergência para hospitalização ou descarga. Considerando que caminhos dos pacientes são feitos com uma maca ou cadeira de rodas empurrada por uma enfermeira, o prazo de execução reduzido leva a um interessante de redução de custos

\section{Artigo 56}

Objetivo - Para compreender a saúde como organizações encontrar a melhor equação de valor, combinando interno e recursos externos em uma concepção modular de serviço, um estudo de caso em uma unidade de cuidados de longo prazo do start-up com formato inovador, grandes níveis de personalização e seguindo uma estratégia de terceirização foi realizado

Conclusão - Este estudo contribui para uma compreensão mais ampla do conceito "leagile" associado a uma estratégia de terceirização operacional. Além disso, ele também oferece novas perspectivas para o conceito de modularidade em configurações de serviços em um serviço complexo como cuidados de saúde

\section{Artigo 57}

Objetivo - O objetivo deste trabalho é discutir como um sistema de medição de desempenho chamado "o modelo de fluxo" é projetado para medir as mudanças no sentido do pensamento Lean em serviços de saúde Conclusão - O artigo encontra-se que o pensamento enxuto é aplicável nas configurações de cuidados de saúde, e que o modelo de fluxo é uma ferramenta adequada para acompanhar estas iniciativas. No entanto, argumenta que o modelo de fluxo deve ser equilibrado com outras medições para receber uma visão completa do desempenho Lean

\section{Artigo 58}

Objetivo - Este artigo visa focar facilitando a melhoria da qualidade em grande escala nos cuidados de saúde, e especificamente compreender mais sobre os desafios conhecidos associados a implementação de inovações Lean: receptividade, a complexidade dos processos de adoção, provas da inovação e incorporar a mudança.

Conclusão - Embora a enfermaria produtiva foi amplamente apoiada, partes interessadas em diferentes níveis identificaram diversos facilitadores e desafios para implementação. Questões-chave para todas as partes interessadas foram tempo de perda para trabalhar no programa e apresentando provas do impacto sobre a equipe, pacientes e ambientes de ala

\section{Artigo 59}

Objetivo - O objetivo deste estudo é explorar a ligação entre associações de ator dinâmico através de um caso de implementação do pensamento enxuto na área da saúde e melhoria contínua (CI)

Conclusão - Este trabalho estudou o papel de atores e suas associações dinâmicas na execução CI na área da saúde, por meio de um caso de implementação do pensamento Lean no Reino Unido NHS. Ele sugeriu que CI implementação depende o surgimento de uma rede de Lean -favorecimento de associações entre atores. Esta rede estabelece uma CI comportamento/cultura através a tradução contínua das identidades dos atores opostos em Lean e, posteriormente, CI princípios 


\section{Artigos}

Objetivo - A base de atendimento em centros de fibrose cística (CF), com resultados clínicos superiores, como com acuidade reduzida de doença episódica e incidência de internações, é frequentes encontros clínicos juntamente com terapias agressivas. No entanto, a ineficiência na estrutura de prática clínica impede ótima utilização de recursos. Para diminuir o tempo sem valor agregado, definido como o tempo que um paciente passa sozinho na sala de exames, sem alterar o tempo provedores passam a cuidar de um paciente, a aplicação de métodos Lean foi usada para ver se reduzindo a variação poderia diminuir significativamente o prazo de execução, considera-se o comprimento de uma visita do paciente, dentro de um ambiente de clínica $\mathrm{CF}$

Conclusão - Análises de capacidade de base revelaram apenas 19,3\% das povoações fazem acta foram concluídas em 60 min ou menos, com média e mediana visita vezes de 81 e 84 min, respectivamente. Análises de capacidade final demonstraram que $41,5 \%$ das visitas dos pacientes foram concluídas em 60 min ou menos, $23 \%$ maior que a capacidade da linha de base. Média e mediana visitam vezes diminuídas 10 min por visita. Os esforços de pesquisa aumentaram a capacidade disponível por 500 pacientes visitas por ano, representando uma receita adicional de mais de US\$ 165.000 anualmente sem custos administrativos adicionais incorridos

\section{Artigo 61}

Objetivo - Acesso do paciente aos recursos de saúde geralmente começa com o agendamento de uma consulta com um médico ou outro provedor. Um ineficiente sistema de agendamento leva a atrasos desnecessários na prestação de cuidados para a frustração por se referir a médicos e pacientes. As ferramentas do pensamento enxuto para avaliar nosso atual sistema de agendamento, remover os procedimentos e processos de desperdício e implementar um sistema mais eficiente e eficaz

Conclusão - Aumentou o valor para os pacientes, que beneficiam de acesso atempado mais cuidado e maior satisfação

Dentre os 61 documentos do portfólio, alguns fizeram uma revisão bibliográfica e analisaram casos em que o Lean já havia sido aplicado. Outros fizeram proposta de melhorias nos respectivos processos estudados. Além disso, nota-se que a filosofia Lean é bastante empregada em várias áreas da saúde, porém nos documentos do portfólio nenhum desses trabalhos explicou detalhadamente como utilizar o Lean.

\section{Conclusão}

Conforme apresentado, o presente artigo teve como objetivo analisar na literatura qualificada estudos referentes a temática de Lean na área da saúde, a fim de verificar como esta filsofia tem sido trabalhada na prática.

Desta forma, puderam ser observados por meio do portfólio trabalhos práticos e teóricos. Vale destacar que a maior parte deles eram práticos, no entanto esses não apresentaram detalhadamente como foi implementada a filosofia Lean no setor de saúde. Percebeu-se que o pensamento Lean tem sido aplicada com sucesso em uma ampla variedade de serviços voltado a saúde. Para melhor perceber os benefícios potenciais, organizações de saúde precisam envolver diretamente a gerência, trabalho em divisões funcionais, prosseguir a criação de valor para os pacientes e outros clientes e sustentar uma visão de longo prazo de melhoria contínua.

Vale lembrar que o enquadramento dos fatores com os artigos foi realizado com base na leitura dos artigos e interpretação da autora, não excluindo a possibilidade de haver abordagens diferentes e até mesmo mais minuciosas para tal análise. Além disso, o trabalho consultou apenas duas bases de dados, portanto os resultados e discussões aqui realizados correspondem a essa limitação de consulta.

Como trabalhos futuros, sugere-se o avanço das pesquisas para complementar e melhorar o que já tem sido realizado, como é o caso de aplicações práticas do Lean voltado aos serviços de saúde. Sugere-se também fazer um trabalho teórico com auxílio mais base de dados e também realizar um enquadramento detalhado e estruturado dos artigos que se propõem a essa temática. Por fim, outra sugestão é desenvolver um estado explicando detalhadamente como utilizar a filosofia Lean. 
AL-ARAIDAH, O.; MOMANI, A.; KHASAWNEH, M.; MOMANI, M. Lead-time reduction utilizing lean tools applied to healthcare: the inpatient pharmacy at a local hospital. Journal for healthcare quality: official publication of the National Association for Healthcare Quality, 2010.

ARONSSON, H.; ABRAHAMSSON, M.; SPENS, K. Developing lean and agile health care supply chains. Supply Chain Management-An International Journal, 2011.

ATKINSON, P.; MUKAETOVA-LADINSKA, E. B. Nurse-led liaison mental health service for older adults: Service development using lean thinking methodology. Journal of psychosomatic research, 2012.

BASSUK, J. A.; WASHIngton, I. M. The A3 Problem Solving Report: A 10-Step Scientific Method to Execute Performance Improvements in an Academic Research Vivarium. PLOS ONE, 2013.

BATCA, V.; IOANAS, C.; BITCA, T.A. Hospital Government-Conceptualization and Instrumentation. Metalurgia International, 2009.

BEN-TOVIM, D. I.; BASSHAM, J. E.; BENNETT, D. M.; DOUGHERTY, M. L.; MARTIN, M. A.; O'NEILL, S. J.; SINCOCK, J. L. ; SZWARCBORD, M. G. Redesigning care at the Flinders Medical Centre: clinical process redesign using "lean thinking". Medical Journal of Australia, 2008.

BEN-TOVIM, D. I.; BASSHAM, J. E.; BOLCH, D.; MARTIN, M. A.; DOUGHERTY, M.; SZWARCBORD, M. Lean thinking across a hospital: redesigning care at the Flinders Medical Centre. Australian Health Review, 2007.

BROWN, T.; DUTHE, R. Getting 'Lean': hardwiring process excellence into Northeast Health. Journal of healthcare information management: JHIM, 2009.

BURGESS, N.; RADNOR, Z. Evaluating Lean in healthcare. International Journal of Health Care Quality Assurance, 2013.

CAMPBELL, R. J.; GANTT, L.; CONGDON, T. Teaching workflow analysis and lean thinking via simulation: a formative evaluation. Perspectives in health information management / AHIMA, American Health Information Management Association, 2009.

CANKOVIC, M.; VARNEY, R. C.; WHITELEY, L.; BROWN, R.; D'ANGELO, R.; CHITALE, D.; ZARBO, R. J. The Henry Ford Production System: LEAN Process Redesign Improves Service in the Molecular Diagnostic Laboratory A Paper from the 2008 William Beaumont Hospital Symposium on Molecular Pathology. Journal of Molecular Diagnostics, 2009.

CARTER, P. M.; DESMOND, J. S.; AKANBOBNAAB, C.; OTENG, R. A.; ROMINSKI, S. D.; BARSAN, W. G.; CUNNINGHAM, R. M. Optimizing Clinical Operations as Part of a Global Emergency Medicine Initiative in Kumasi, Ghana: Application of Lean Manufacturing Principals to Low-resource Health. Academic emergency medicine, 2012.

CHIARINI, A. Waste savings in patient transportation inside large hospitals using lean thinking tools and logistic solutions. Leadership in Health Services, 2013.

CIMA, R. R.; BROWN, M. J.; HEBL, J. R.; MOORE, R.; ROGERS, J. C.; KOLLENGODE, A.; AMSTUTZ, G. J.; WEISBROD, C. A.; NARR, B. J.; DESCHAMPS, C. Use of Lean and Six Sigma Methodology to Improve Operating Room Efficiency in a High-Volume Tertiary-Care Academic Medical Center. Journal of the American College of Surgeons, 2011. 
DE MAST, J.; KEMPER, B.; DOES, R. J. M. M.; MANDJES, M.; VAN DER BIJL, Y. Process Improvement in Healthcare: Overall Resource Efficiency. Quality and Reliability Engineering International, 2011.

DICKSON, E. W.; ANGUELOV, Z.; VETTERICK, D.; ELLER, A.; SINGH, S. Use of Lean in the Emergency Department: A Case Series of 4 Hospitals. Annals of Emergency Medicine, 2009.

DUNDAS, N. E.; ZIADIE, M. S.; REVELL, P. A.; BROCK, E.; MITUI, M.; LEOS, N. K.; ROGERS, B. B. A Lean Laboratory Operational Simplicity and Cost Effectiveness of the Luminex xTAG (TM) Respiratory Viral Panel. Journal of Molecular Diagnostics, 2011.

FORD, A. L.; WILLIAMS, J. A.; SPENCER, M.; MCCAMMON, C.; KHOURY, N.; SAMPSON, T. R; PANAGOS, P.; LEE, J. M. Reducing Door-to-Needle Times Using Toyota's Lean Manufacturing Principles and Value Stream Analysis. STROKE, 2013.

From cars to catheters: Adapting lean principles within a healthcare environment. Development and Learning in Organisations, 2007.

GRABAN, M. Lean hospitals: improving quality, patient safety, and employee satisfaction. New York, Productivity Press, 2008.

GRABAN, M.; PADGETT, S. Lean Laboratories: Competing with Methods from Toyota. Labmedicine, 2008.

GROUT, J. R.; TOUSSAINT, J. S. Mistake-proofing healthcare: Why stopping processes may be a good start. Business Horizons, 2010.

GROVE, A. L.; MEREDITH, J. O.; MACINTYRE, M.; ANGELIS, J.; NEAILEY, K. Lean implementation in primary care health visiting services in National Health Service UK. Quality \& Safety in Health Care, 2010.

GUIMARÃES, C. M.; DE CARVALHO, J. C. Outsourcing in healthcare through process modularization- A lean perspective. International Journal of Engineering Business Management, 2012.

HEITMILlER, E. S.; HILL, R. B.; MARSHALL, C. E.; PARSONS, B. J.; BERKOW, L. C.; BARRASSO, C. A.; ZINK, E. K.; NESS, P. M. Blood wastage reduction using Lean Sigma methodology. Transfusion, 2010.

HINTZEN, B. L.; KNOER, S. J.; VAN DYKE, C. J.; MILAVITZ, B. S. Effect of lean process improvement techniques on a university hospital inpatient pharmacy. American Journal of HealthSystem Pharmacy, 2009.

HUMMEL, J.; EVANS, P. C.; LEE, H. Medication reconciliation in the emergency department: opportunities for workflow redesign. Quality \& Safety in Health Care, 2010.

HYDES, T.; HANSI, N.; TREBBLE, T. M. Lean thinking transformation of the unsedated upper gastrointestinal endoscopy pathway improves efficiency and is associated with high levels of patient satisfaction. BMJ Quality \& Safety, 2012.

IANNETTONI, M.D.; LYNCH, W. R.; PAREKH, K. R.; MCLAUGHLIN, K. A. Kaizen Method for Esophagectomy Patients: Improved Quality Control, Outcomes, and Decreased Costs. Annals of Thoracic Surgery, 2011. 
IERACI, S.; DIGIUSTO, E.; SONNTAG, P.; DANN, L.; FOX, D. Streaming by case complexity: Evaluation of a model for emergency department Fast Track. Emergency Medicine Australasia, 2008.

IMAI, M. Kaisen: A estratégia para o sucesso competitivo. São Paulo: Instituto IMAM, 1986 - $5^{\text {a }}$ edição 1994.

KIM, C. S.; SPAHLINGER, D. A.; KIN, J. M.; BILLI, J. E. Lean health care: What can hospitals learn from a world-class automaker?. Journal of Hospital Medicine, 2006.

KITCHENHAM, B. Procedures for Performing Systematic Reviews. Joint Technical Report, Software Engineering Group, Keele University and Empirical Software Eng., Nat'l ICT Australia, 2004.

KOLLBERG, B. ;DAHLGAARD, J. J. ;BREHMER, P. O. Measuring lean initiatives in health care services: Issues and findings. International Journal of Productivity and Performance Management, 2007.

KRUSKAL, J. B.; REEDY, A.; PASCAL, L.; ROSEN, M. P.; BOISELLE, P. M. Quality Initiatives Lean Approach to Improving Performance and Efficiency in a Radiology Department. Radiographics, 2012.

LAGANGA, L.R. Lean service operations: Reflections and new directions for capacity expansion in outpatient clinics. Journal of Operations Management, 2011.

L'HOMMEDIEU, T.; KAPPELER, K. Lean methodology in i.v. medication processes in a children's hospital. American Journal of Health-System Pharmacy, 2010.

MAZUR, L.; MCCREERY, J.; ROTHENBERG, L. Facilitating Lean Learning and Behaviors in Hospitals During the Early Stages of Lean Implementation. EMJ-Engineering Management Journal, 2012.

MAZZOCATO, P. ;HOLDEN, R. J.;BROMMELS, M. ;ARONSSON, H. ;BÄCKMAN, U. ;ELG, M. ;THOR, J. How does lean work in emergency care? A case study of a lean-inspired intervention at the Astrid Lindgren Children's hospital, Stockholm, Sweden. BMC Health Services Research, 2012.

MAZZOCATO, P.; HOLDEN, R.J.; BROMMELS, M.; ARONSSON, H.; BACKMAN, U.; ELG, M.; THOR, J. How does lean work in emergency care? A case study of a lean-inspired intervention at the Astrid Lindgren Children's hospital, Stockholm, Sweden. BMC Health Services Research, 2012.

MAZZOCATO, P.; SAVAGE, C.; BROMMELS, M.; ARONSSON, H.; THOR, J. Lean thinking in healthcare: a realist review of the literature. Quality \& Safety in Health Care, 2010.

MORROW, E.; ROBERT, G.; MABEN, J.; GRIFFITHS, P. Implementing large-scale quality improvement: Lessons from The Productive Ward: Releasing Time to Care. International Journal of Health Care Quality Assurance, 2012.

NG, D.; VAIL, G.; THOMAS, S.; SCHMIDT, N. Applying the Lean principles of the Toyota Production System to reduce wait times in the emergency department. Canadian Journal of Emergency Medicine, 2010.

NIEMEIJER, G. C.; TRIP, A.; AHAUS, K. T. B.; DOES, R. J. M. M.; WENDT, K. W. Quality in Trauma Care: Improving the Discharge Procedure of Patients by Means of Lean Six Sigma. Journal of Trauma-Injury Infection and Critical Care, 2010. 
PAPADOPOULOS, T. Continuous improvement and dynamic actor associations: A study of lean thinking implementation in the UK National Health Service. Leadership in Health Services, 2011.

PAPADOPOULOS, T.; RADNOR, Z.; MERALI, Y. The role of actor associations in understanding the implementation of Lean thinking in healthcare. International Journal of Operations \& Production Management, 2011.

RADNOR, Z.J.; HOLWEG, M.; WARING, J. Lean in healthcare: The unfilled promise?. Social science \& medicine, 2012.

RECHEL, B.; WRIGHT, S.; BARLOW, J.; MCKEE, M. Hospital capacity planning: from measuring stocks to modelling flows. Bulletin of the World Health Organization, 2010.

ROBINSON, S.; RADNOR, Z. J.; BURGESS, N.; WORTHINGTON, C. SimLean: Utilising simulation in the implementation of lean in healthcare. European journal of operational research, 2012.

RUTLEDGE, J.; XU, M.; SIMPSON, J. Application of the Toyota Production System Improves Core Laboratory Operations. American Journal of Clinical Pathology, 2010.

SANKOFF, J.; TAUB, J.; MINTZER, D. Accomplishing Much in a Short Time: Use of a Rapid Improvement Event to Redesign the Assessment and Treatment of Patients with Alcohol Withdrawal. American journal of medical quality, 2013.

SEIDL, K. L.; NEWHOUSE, R. P. The Intersection of Evidence-Based Practice with 5 Quality Improvement Methodologies. Journal of nursing administration, 2012.

SMITH, C.; WOOD, S.; BEAUVAIS, B. Thinking lean: implementing DMAIC methods to improve efficiency within a cystic fibrosis clinic. Journal for healthcare quality: official publication of the National Association for Healthcare Quality, 2011.

TEICHGRABER, U. K.; DE BUCOURT, M. Applying value stream mapping techniques to eliminate non-value-added waste for the procurement of endovascular stents. European journal of radiology, 2012.

TOUSSAINT, J. Writing The New Playbook For US Health Care: Lessons From Wisconsin. Health Affairs, 2009.

VAN LENT, W. A. M.; GOEDBLOED, N.; VAN HARTEN, W. H. Improving the efficiency of a chemotherapy day unit: Applying a business approach to oncology. European Journal of Cancer, 2009.

VAN VLIET, E. J.; BREDENHOFF, E.; SERMEUS, W.; KOP, L. M.; SOL, J. C. A.; VAN HARTEN, W. H. Exploring the relation between process design and efficiency in high-volume cataract pathways from a lean thinking perspective. International Journal for Quality in Health Care, 2011.

VAN VLIET, E. J.; SERMEUS, W.; VAN GAALEN, C. M.; SOL, J. C. A.; VISSERS, J. M. H. Efficacy and efficiency of a lean cataract pathway: a comparative study. Quality \& Safety in Health Care, 2010.

VILLENEUVE, C. Fujitsu's Lean Solutions Group -Lean Healthcare in Canada. Fujitsu Scientific \& Technical Journal, 2011.

WARING, J.J; BISHOP, S. Lean healthcare: Rhetoric, ritual and resistance. Social Science \& Medicine, 2010. 
WARNER, C. J. ; WALSH, D. B.; HORVATH, A. J.; WALSH, T. R.; HERRICK, D.P.; PRENTISS, S. J.; POWELL, R. J. Lean principles optimize on-time vascular surgery operating room starts and decrease resident work hours. Journal of vascular surgery, 2013.

WILSON, G. Implementation of releasing time to care - the productive ward. Journal of Nursing Management, 2009.

WOJTYS, E. M. ;SCHLEY, L. ;OVERGAARD, K. A. ;AGBABIAN, J. Applying lean techniques to improve the patient scheduling process. Journal for healthcare quality: official publication of the National Association for Healthcare Quality, 2009.

WOMACK, J. P.; JONES, D. T.; ROOS, D. A máquina que mudou o mundo. Rio de Janeiro: Editora Campus, 1992.

WOMACK, J.P.; BYRNE, A.P.; FIUME, O.J.; KAPLAN, G.S.; TOUSSANT, J.; MILLER, D. Going lean in healthcare. Innovation Series 2005, Institute for Healthcare Improvement, 2005.

YEH, H. L.; LIN, C. S.; SU, C.T.; WANG, P. C. Applying lean six sigma to improve healthcare: An empirical study. African journal of business management, 2011.

YOUNG, T. P.; MCCLEAN, S. I. A critical look at Lean Thinking in healthcare. Quality \& Safety in Health Care, 2008.

YOUSRI, T. A.; KHAN, Z.; CHAKRABARTI, D.; FERNANDES, R.; WAHAB, K. Lean thinking: Can it improve the outcome of fracture neck of femur patients in a district general hospital?. InjuryInternational Journal of the Care of the Injured, 2011. 